\title{
Turismo y sostenibilidad ambiental y social a través del etnomarketing en Isla Grande (Archipiélago de Nuestra Señora del Rosario, Colombia)
}

\section{Tourism and environmental and social sustainability through ethnomarketing in Isla Grande (Archipelago of Nuestra Señora del Rosario, Colombia)}

\author{
Alejandro Villarreal-Gómez \\ avillarrealg@unicartagena.edu.co @ 0000-0002-8729-8625 \\ G.I. Ciencia, Tecnología y Sociedad, Universidad de Cartagena de Indias (Colombia). \\ Claustro San Agustín. Carrera 6, Calle de la Universidad 36-100. Colombia \\ Paola Mouthón-Ramos \\ pmouthonr@unicartagena.edu.co @ 0000-0002-3114-9380 \\ G.I. Tecnología de la Información, Emprendimiento y Sociedad, Universidad de Cartagena de Indias (Colombia). \\ Avda. del Consulado, Calle 30, n 48.152 Campus Piedra de Bolívar, Colombia \\ José Manuel Jurado-Almonte \\ jurado@uhu.es @0000-0001-8948-3165 \\ G.I. Instituto de Desarrollo Local, Universidad de Huelva (España) \\ Avda. 3 de marzo, Campus El Carmen. 21071 Huelva, España
}

INFO ARTÍCULO

Recibido: 15-05-2021

Revisado: 26-06-2021

Aceptado: 05-07-2021

PALABRAS CLAVE

Ecoturismo

Etnomarketing

Sostenibilidad ambiental

Afrodescendientes.

\section{RESUMEN}

Isla Grande (Archipiélago de Nuestra Señora del Rosario, Colombia) tiene varias particularidades que justifican su investigación. Destaca su riqueza ambiental y de arrecifes coralinos, por lo que ha sido considerado como uno de los parques naturales nacionales más importantes en el Caribe colombiano. A esto se une que sus habitantes son afrodescendientes y que la propiedad del territorio es de carácter colectivo. Ello conlleva un particular proceso de organización local autónomo para establecer un modelo de gestión territorial y de desarrollo local.

El turismo se ha convertido en una oportunidad, pero también constituye una amenaza para el medio natural. De esta manera, se ha querido planificar y gestionar esta actividad sobre la base del ecoturismo y el etnomarketing.

En esta investigación hay un compromiso de la Universidad de Cartagena de Indias con la sostenibilidad ambiental de este singular territorio. Se ha trabajado con encuestas y entrevistas a nativos, turistas y empresarios. También, ha sido importante la observación directa y la realización de talleres participativos para conocer y diagnosticar la actividad turística. Ello ha permitido, entre otras investigaciones, formular un plan de marketing en el que se promocionen y se den a conocer las potencialidades ecoturísticas de la isla, los saberes ancestrales de los nativos, entre otros aspectos, y contribuir, de la mano de los actores locales, a su sostenibilidad ambiental.

\section{ABSTRACT}

Isla Grande (Archipelago of Nuestra Señora del Rosario, Colombia) has several peculiarities that justify its investigation. Its environmental wealth and coral, reefs stand out, which is why it has been considered one of the most important national natural parks in the Colombian Caribbean. To this is added that its inhabitants are Afro-descendants and that the ownership of the territory is collective. This entails a particular autonomous local organization process to establish a territorial management and local development model. 


\begin{abstract}
Tourism has become an opportunity, but it also constitutes a threat to the natural environment. In this way, it has been wanted to plan and manage this activity on the basis of ecotourism and ethnomarketing.

In this research there is a commitment from the University of Cartagena de Indias with the environmental sustainability of this unique territory. It has worked with surveys and interviews with natives, tourists and businessmen. Direct observation and participatory workshops have also been important to understand and diagnose tourist activity. This has allowed, among other investigations, to formulate a marketing plan in which the island's ecotourism potential, the ancestral knowledge of the natives, among other aspects, is promoted and made known, and to contribute hand in hand with the actors premises with their environmental sustainability.
\end{abstract}

\title{
1. INTRODUCCIÓN Y JUSTIFICACIÓN
}

El turismo se convierte en una oportunidad para muchos territorios, dadas las posibilidades de arrastre que tiene en las economías locales y en el empleo. Todos ellos ponen sus recursos y atractivos aspirando a un ansiado impulso turístico en un mercado mundial muy competitivo.

Sin embargo, vemos como en Latinoamérica y en la península Ibérica abundan destinos turísticos especializados que son visitados de forma masiva por foráneos, afectando el núcleo cultural y el legado de los grupos étnicos que allí residen (Pereiro, 2020), los cuales se ven en la disyuntiva de conservar sus tradiciones o continuar fomentando las actividades económicas que les generan ingresos para el sostenimiento de sus familias. Es así como el Etnomarketing, bien utilizado, se considera una alternativa que puede ayudar a equilibrar el desarrollo turístico sin tener que sacrificar las costumbres locales, ya que estas se constituyen en el principal atractivo para los visitantes, quienes aprenden de la forma de vida y saberes de los nativos, generando respeto por el conocimiento ancestral de la comunidad.

El etnomarketing implica entonces desde el turismo una óptica integradora para las tres funciones del marketing (Páramo, 2015): entender las necesidades y el sentir de los consumidores que desean vivir una experiencia y con un gran recordatorio, conquistar compradores a través del "consumo" de los aspectos socioculturales del destino y fidelizar clientes ante las características únicas del sitio y sus habitantes. Como cita Flavio Salas (2018), "la potencia del etnomarketing proviene de la estrategia y parte desde las raíces mismas de la sociedad" se considera un proceso social desde la oferta de los nativos que aprenden a valorar sus saberes ancestrales al hacer compatible la salvaguarda de las tradiciones culturales con su uso turístico y el desarrollo de las economías locales, manteniendo el estilo de vida.

Colombia, país con gran biodiversidad, paisajes y patrimonio cultural, venía en aumento en cuanto a la cifra de entrada de turistas internacionales en el momento de realizar el estudio', aspecto que posteriormente fue truncado en el último año por la crisis del Covid 19, como en tantos otros mercados turísticos. Dentro de sus destinos regionales, destaca Cartagena de Indias (Departamento de Bolívar), a orillas del Mar Caribe, como así indican la actividad de su aeropuerto ${ }^{2}$ y su puerto (turismo de crucero) ${ }^{3}$, tanto para el turismo internacional como el nacional.

Menos afectada por las conocidas convulsiones del resto de Colombia, esta ciudad se ha convertido en el principal destino turístico del país. Se trata de la primera ciudad colombiana en ser declarada Patrimonio Histórico y Cultural de la Humanidad (1984) gracias a su impresionante conjunto monumental. Su centro histórico amurallado es el más extenso de Iberoamérica. Además, posee en sus inmediaciones numerosas playas e islas de enorme atractivo y con posibilidades de ofrecer diversas ofertas y productos turísticos. En

1. El número de visitantes no residentes que llegaron a Colombia fue de 4.515 .932 , un crecimiento del $2,7 \%$ con respecto a 2018. Se trata de unas cifras récord (MINCIT, 2019) y corresponde al período de realización del estudio, comportamiento que se mantuvo hasta antes de la pandemia COVID-19.

2. 2019 fue un año de cifras récord para el turismo en Colombia. El número de visitantes no residentes que llegaron al país fue de 4.515.932, un crecimiento del 2,7 \% con respecto a 2018 con una ocupación hotelera del $57,8 \%$ de acuerdo a los datos del Ministerio de Comercio, Industria y Turismo.

3. Por vía marítima, Cartagena recibió 612.217 visitantes en la temporada de cruceros de julio de 2018 a junio de 2019 (SITCAR). 
consecuencia, ha experimentado un sobresaliente crecimiento urbano-turístico, que configura una nueva Cartagena de elevados bloques residenciales a pie de playa (Bocagrande y El Laguito), muy parecida al modelo urbanístico de Miami (EE.UU.), pero con el cercano encanto de un caserío colonial intramuros que parece volver a la Cartagena colonial.

El interés turístico de la ciudad se vuelca también hacia otros espacios dentro del mismo Distrito municipal de Cartagena, como son la península de Barú, isla de Tierra Bomba y el Archipiélago de las Islas del Rosario y, dentro de las mismas, Isla Grande, la de mayor extensión, la cual será el ámbito territorial preferente de esta investigación (figura 1).

Isla Grande y el conjunto del archipiélago del Rosario fueron declarados Parque Natural Nacional. Con ello, se ponen límites a un desarrollo urbano-turístico similar al acontecido en la capital municipal. Esta isla, históricamente, ha estado sumida en la pobreza, con limitaciones infraestructurales importantes, como - la escasez de agua potable y una dependencia de Cartagena, desde donde se importan la mayor parte de los productos domésticos y de subsistencia. En las últimas décadas la llegada de turistas y visitantes, y que en conjunto suponen un millón de viajeros según datos del Ministerio de Industria, Comercio y Turismo (MINCIT, 2019), abre nuevas oportunidades económicas para sus habitantes, quienes no quieren perder sus señas de identidad, ni ver reducida su calidad ambiental, o perder su propiedad colectiva sobre el territorio. Por tanto, han acogido el modelo del ecoturismo como una fórmula compatible con la sostenibilidad ambiental, con nuevas opciones, como los deportes náuticos, el senderismo, el avistamiento de aves, etc., que pueden generar ingresos y empleo.

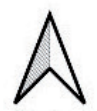

Isla Grande, Archipíelago Nuestra Señora del Rosario. Cartagena de Indias

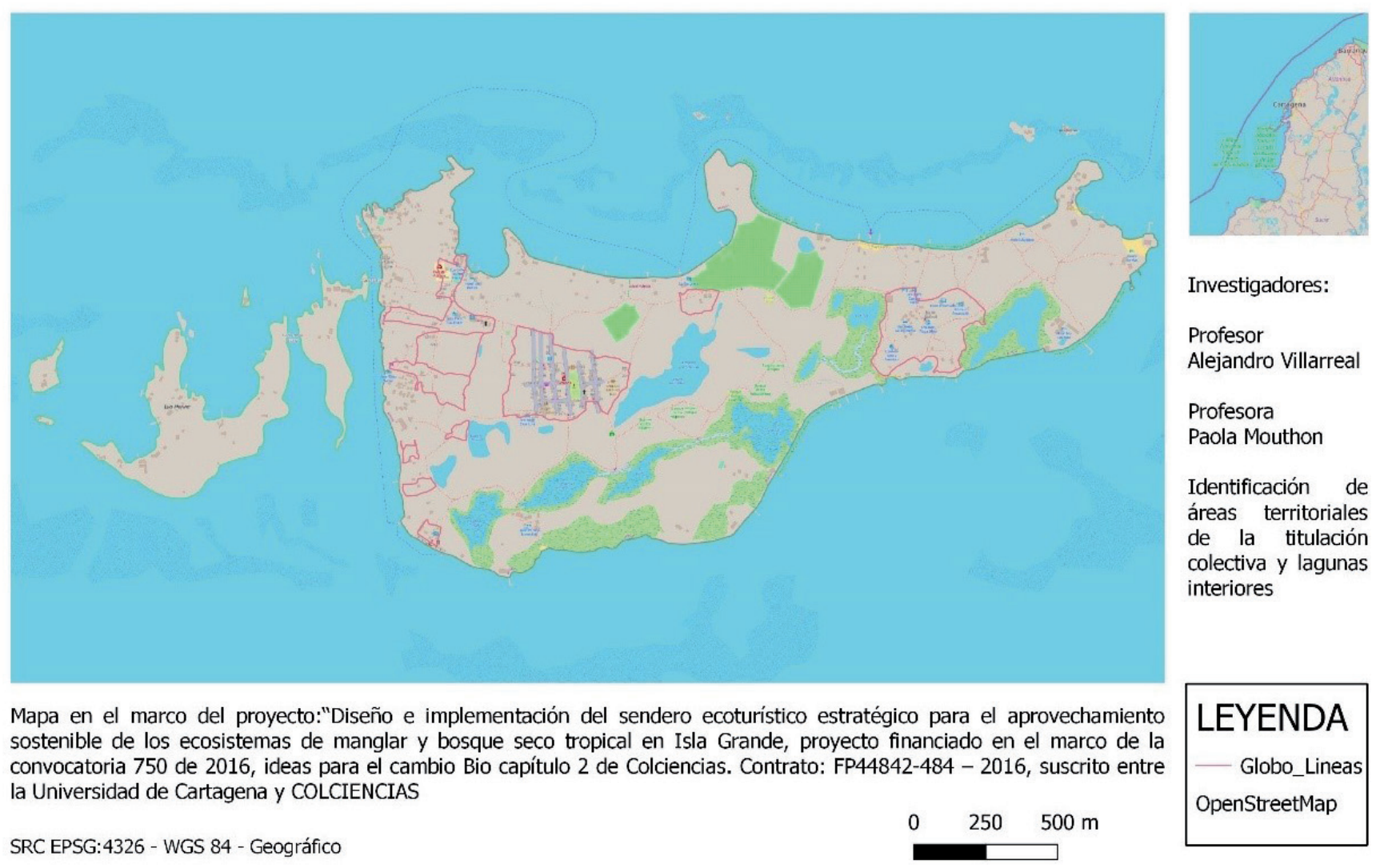

Figura 1. Localización del Archipiélago de Islas del Rosario (Distrito de Cartagena-Colombia). Fuente: Mapa elaborado por los autores Alejandro Villarreal y Paola Mouthón en el marco del proyecto "Diseño e Implementación del sendero ecoturístico estratégico para el aprovechamiento sostenible de Isla Grande”, financiado por Colciencias (2019). 
Otra singularidad es su población nativa, compuesta mayoritariamente por personas de origen afrodescendiente, que ancestralmente encontraron en Isla Grande posibilidades de subsistencia y también de libertad. Después de una larga lucha de reivindicaciones y derechos, la Ley 70 de 1993 reconoció a las comunidades negras que habían venido ocupando tierras baldías el derecho a la propiedad colectiva. Con esta Ley llegó también la creación de unos Consejos Comunitarios que gestionan este territorio. Sus principales funciones son velar por la protección de los derechos de la propiedad colectiva, resguardo de la memoria ancestral, el aprovechamiento y conservación de los recursos naturales.

Por tanto, se dan en este territorio diversas circunstancias, muy singulares e interesantes, dignas de ser estudiadas transversalmente desde diversos planos disciplinares (geografía y antropología, principalmente) y que justifican su investigación y cimientan los pilares para la utilización del etnomarketing:

- Territorio con altos valores medioambientales y protegido por una legislación medioambiental específica.

- Llegada de intereses económicos y turísticos foráneos que podrían amenazar los recursos naturales del territorio.

- Población nativa afrodescendiente, tradicionalmente muy pobre y marginada, pero que ahora recobra un nuevo protagonismo para luchar por preservar sus costumbres y fomentar el respeto por su cultura.

- Administración y gestión territorial a escala local, organizada principalmente por el Consejo Comunitario insular, en el que delegan las autoridades municipales y gubernamentales, aunque confluyen otras administraciones y actores a escalas nacional, regional y local.

- Propiedad de la tierra mayormente de tipo comunal, aunque hay algunos arrendatarios.

- Apuesta por un desarrollo sostenible del turismo (ecoturismo), preservando la conservación de los recursos naturales.

- Fuerte identidad cultural, que se plasma en un potente asociacionismo y sentido de la colectividad (etnodesarrollo).

De esta manera, el objetivo de esta aportación es estudiar este escenario territorial, sus especificidades naturales, sociales y culturales, y las nuevas posibilidades turísticas que brinda el ecoturismo, utilizando para ello el etnomarketing en este ámbito territorial.

Se parte inicialmente de la hipótesis de que el aprovechamiento de las riquezas naturales y culturales de Isla Grande pueden generar factores diferenciadores a otros destinos turísticos a través de una oferta de experiencias únicas. Relacionado con ésta, una segunda hipótesis es que posee importantes potencialidades ecoturísticas que han de ser abordadas de forma integral y planificadas si se quiere desarrollar y posicionar nuevos productos ecoturísticos y fortalecer los ya existentes. Y como tercera hipótesis, consideramos que el ecoturismo se convierte en un modelo de desarrollo turístico que puede ser potencializada a través del etnomarketing como herramienta de promoción del destino.

También, hay un compromiso por parte de investigadores de la Universidad de Cartagena de apostar por este modelo turístico sostenible, en los que se ha contado con la participación activa de la población nativa, organizada por el Consejo Comunitario, y con todos los actores económicos y asociativos de la isla, quienes son los principales beneficiarios. Ese particular compromiso investigador, social y personal con el territorio ha dado como resultado también tesis doctorales sobre estos espacios habitados mayoritariamente por población negra, con tierras cuya propiedad ha sido declarada como comunal y con la amenaza de modelos de crecimiento urbano-turísticos más transformadores. Son los casos de Isla Grande (Villarreal, 2017) y de La Boquilla (Llamas, 2020), al este de la ciudad cartagenera.

\section{MARCO TEÓRICO: ETNOMARKETING, ETNODESARROLLO Y ECOTURISMO}

Existen tres conceptos sobre los que gira esta investigación que merecen especial atención en su conceptualización y adaptación, son los de etnomarketing, etnodesarrollo y ecoturismo. 
El etnomarketing confiere a la cultura una gran importancia tanto desde la perspectiva de los ofertantes como de los demandantes turísticos. Es un proceso económico (Páramo, 2015), como también de generación de conocimiento basado en la comprensión de una sociedad específica a partir de la religión, historia, economía, política, sociedad, arte, lingüística, esoterismo, etc. (Ortiz, 2016).

En este sentido, hay una apuesta en el etnomarketing como una manera de potenciar el ecoturismo y etnodesarrollo de la isla, valiéndose de la tradición cultural de los habitantes, además de los valores medioambientales. Este enfoque permite conservar tradiciones y saberes ancestrales, transmitirlos a los visitantes para despertar su interés y respeto hacia los mismos, evitando que caigan en manos de terceros mediante un turismo depredador (Quintana, 2020) que pone en riesgo la supervivencia de este patrimonio inmaterial que merece respeto.

El desarrollo sostenible supone, además, pasar de un turismo de masas depredador hacia uno más saludable e interesante tanto para los visitantes como para el propio destino (Martínez, 2020), logrando un esquema donde todos ganan al permitir a la población autóctona sentirse orgullosa de sus saberes ancestrales, transmitirlos de padres a hijos ya que los más jóvenes valoraran lo tradicional que les permite también un desarrollo económico local. Por su parte, los visitantes tendrán una experiencia única al interactuar con las comunidades, conocer su forma de vida, costumbres y creencias, obteniendo un conocimiento integral de cada sitio, lo que enriquecerá su experiencia de viaje. Es aquí donde el etnomarketing es una herramienta fundamental para lograr esta conexión.

No existe un plan de etnomarketing único, sino que éste ha de adaptarse a cada contexto geográfico y cultural y a los objetivos propios. Para el desarrollo de las estrategias de este proyecto, se tuvo en cuenta un modelo propio resultante de la adaptación de Kotler y Keller (2012) y del propuesto por Giraldo y Juliao (2016), en el que se parte del diagnóstico del destino turístico con el objeto de identificar los principales objetivos a largo plazo, para así diseñar un plan de acción que tenga como eje principal el etnomarketing y contribuya a lograr el etnodesarrollo de la región.

El término etnodesarrollo se utilizó inicialmente para desarrollar propuestas que impulsen el desarrollo de grupos étnicos específicos (Cortecero et al., 2020), buscando contextualizarlas frente al crecimiento global. Bonfil (1982) fue uno de los primeros en asociar el término con "la capacidad social de un pueblo para construir su futuro, utilizando para ello las enseñanzas de su experiencia histórica, y los recursos reales y potenciales de su cultura, de acuerdo a un proyecto que se adapte a sus propios valores y aspiraciones futuras". En suma, se trata de reconducir un desarrollo y una mejora de vida, pero sin perder los rasgos de identidad cultural.

El turismo patrimonial amplía posibilidades incluyendo el turismo experiencial y el encuentro con lo exótico (...), está siendo una de las principales apuestas productivas para la mejora de las economías locales (De Madariaga, 2019). En este contexto se puede considerar el turismo como "un proceso social y cultural de producción de espacios, significados y experiencias que involucra múltiples dimensiones (políticas, culturales, ambientales, sociales, económicas) y una amplia gama de actores sociales con intereses diversos" (Sosa \& DAbusco, 2020).

En definitiva, el turismo sostenible se basa más en aspectos naturales y no en escenarios construidos donde no hay interacción con la comunidad, aspectos que caracterizan al turismo tradicional, y es aquí donde juega un papel importante el ecoturismo y el turismo alternativo. Sin embargo, se hace necesario que se planifique muy bien para evitar peligros sobre ecosistemas frágiles y las zonas vulnerables (Martínez, 2020).

El ecoturismo se convierte en un nuevo producto turístico que se está potenciando en las dos últimas décadas, muy especialmente en Latinoamérica. Es un producto, pero también un propósito para potenciar algunos enclaves naturales y culturales, pero sin poner en riesgo los elementos ambientales de esos territorios ni los valores culturales de las sociedades nativas.

La Unión Mundial para la Naturaleza (IUCN) define al ecoturismo como "aquella modalidad turística ambientalmente responsable consistente en viajar o visitar áreas naturales relativamente sin disturbar con el fin de disfrutar, apreciar y estudiar los atractivos naturales (paisaje, flora y fauna silvestres) de dichas áreas, así como cualquier manifestación cultural (del presente y del pasado) que puedan encontrarse ahí, a través de un proceso que promueve la conservación, tiene bajo impacto ambiental y cultural y propicia un involucramiento activo y socio económicamente benéfico de las poblaciones locales" (Ceballos-Lascuráin, IUCN, 1996). 
Marchena et al. (1993) afirma que el desarrollo del ecoturismo en áreas protegidas debe afrontarse como un problema de gestión, para el cual es necesario preparar las condiciones necesarias que permitan garantizar esta actividad y promover la conservación de los recursos y valores utilizados para la misma.

Vargas del Río (2010) manifiesta que los proyectos de ecoturismo comunitario han aparecido ante todo en áreas naturales, legalmente protegidas o no, que poseen altos niveles de biodiversidad imputables al conocimiento ancestral y manejo cuidadoso de los pobladores locales y con cierto potencial de mercado al estar ubicados cerca de centros turísticos consolidados. Por otra parte, Molina (2011) refiere las enormes ventajas que tiene un ecoturismo bien llevado y gestionado. Este debe servir a las comunidades locales como fuente de ingresos y contribuir a sensibilizar a todos los agentes involucrados en el turismo, incluidos los propios turistas, en mayor medida con la protección medioambiental. En definitiva, como resaltan Magio y Valdez (2019), el ecoturismo en las áreas naturales protegidas puede contribuir al desarrollo socioeconómico, y servir como incentivo para que la comunidad local participe en iniciativas de conservación.

Estas últimas definiciones cuadran perfectamente con el contexto natural y cultural de Isla Grande: un espacio ambiental que está protegido legalmente, que tiene unos riesgos ambientales, que está muy cercano a un enclave turístico de primer orden (la ciudad de Cartagena de Indias.

\section{MARCO TERRITORIAL Y NORMATIVO}

Ya en el apartado de introducción hemos avanzado algunas de las singularidades del ámbito territorial de Isla Grande.

Esta isla forma parte del Archipiélago de las Islas del Rosario que ocupan 31 islas e islotes en su conjunto y con una superficie en global de 325, 5 ha. Es la más extensa, con 201,8 ha., donde se pueden apreciar tres ecosistemas: las lagunas costeras e interiores, los manglares y el bosque seco tropical (BST). El clima es tropical con altas temperaturas medias (unos $28^{\circ} \mathrm{C}$ a lo largo del año) y humedad relativa (80\%) y una estacionalidad en el ciclo de las precipitaciones, predominantes entre mayo y noviembre y con unos 1.000 mm de media al año.

La población, según datos del Observatorio para el Desarrollo Sostenible (2015), es de aproximadamente 1.000 habitantes, asentados principalmente en el núcleo de Orika, el cual está registrado por la Alcaldía Mayor de Cartagena desde 2005. Históricamente, ha sido una población sumida en la pobreza, que vivía principalmente de la pesca (Prieto, 2010).

Sobre este territorio confluyen distintas administraciones públicas provenientes de diferentes escalas: nacional (Ministerio de Ambiente y Desarrollo Sostenible -MADS-, Agencia Nacional de Tierras -ANT-, Dirección General Marítima -DIMAR-, Instituto de Investigaciones Marinas y Costeras -INVEMAR-, entre otros), regional (Corporación Autónoma Regional del Canal del Dique -CARDIQUE-) y local (Alcaldía de Cartagena, Corporación de Turismo de Cartagena y Consejo Comunitario de Orika en Isla Grande).

Se trata de un territorio de afrodescendientes que se encuentra regido por el Consejo Comunitario, máxima autoridad de administración interna de este singular territorio. Su función es mejorar socialmente su comunidad, a través de la formulación del plan de vida, preservar ambientalmente su territorio mediante la implementación de un plan de manejo ambiental y proteger legalmente su pervivencia cultural y el saber ancestral. Asimismo, tienen un cuerpo de seguridad propio llamado Guardia Cimarrona, formada por personas de edad mayormente senil y reconocidas y respetadas por la comunidad quienes vigilan el cumplimiento del reglamento interno de convivencia.

En síntesis, el Consejo Comunitario administra las tierras comunales que fueron otorgadas mediante titulación colectiva. Ello viene como consecuencia de la Ley 70 de 1993 y del Decreto 1745 de 1995 y entronca con el artículo transitorio $55^{4}$ de la entonces Constitución Política de Colombia de 1991. Se intentaba con la

4. Artículo transitorio 55. Dentro de los dos años siguientes a la entrada en vigencia de la presente Constitución, el Congreso expedirá, previo estudio por parte de una comisión especial que el Gobierno creará para tal efecto, una ley que les reconozca a las comunidades negras que han venido ocupando tierras baldías en las zonas rurales ribereñas de los ríos de la Cuenca del Pacífico, de acuerdo 
misma reconocer la propiedad comunitaria de las denominadas tierras baldías ${ }^{5}$, que ancestralmente han sido ocupadas por poblaciones negras y con el propósito de preservar sus identidades culturales y el fomento de su desarrollo económico y social (Resumen del Art. 1).

Esta Ley se basa en el reconocimiento ancestral y cultural de las poblaciones afrodescendientes. A su vez, sirve de base para el fomento de la organización social de esta población, permitiendo que se vuelvan partícipes y brindándoles autonomía en las decisiones que se tomen en materia de uso y ocupación de sus tierras, contribuyendo al empoderamiento de su historia y cultura.

Por lo anterior, cabe entonces resaltar el artículo $3^{\circ}$ de la Ley 70 donde se fundamentan los siguientes principios:

1. El reconocimiento y la protección de la diversidad étnica y cultural y el derecho a la igualdad de todas las culturas que conforman la nacionalidad colombiana.

2. El respeto a la integralidad y la dignidad de la vida cultural de las comunidades negras.

3. La participación de las comunidades negras y sus organizaciones sin detrimento de su autonomía, en las decisiones que las afectan y en las de toda la Nación en pie de igualdad, de conformidad con la ley.

4. La protección del medio ambiente atendiendo a las relaciones establecidas por las comunidades negras con la naturaleza.

Con la referida Ley no se acabaron los problemas para el reconocimiento comunal de la tierra. Después de varias sentencias judiciales (inicial Sentencia T-680/12 del 27 de agosto de 2012), no será hasta el 13 de mayo de 2014 cuando se conceden a las comunidades afrodescendientes el derecho a la titulación colectiva de las tierras que han ocupado tradicionalmente (Resolución 3393).

Asimismo, Isla Grande forma parte del área protegida del Archipiélago del Rosario, un Parque Nacional Natural de un espacio marítimo-terrestre que se extiende por aproximadamente 120.000 hectáreas, tras sucesivos deslindes (el último es de 2005) y que incluye los anteriores ecosistemas terrestres, pero también las formaciones de arrecifes de coral que son las más importantes de Colombia.

Su protección arranca inicialmente por Acuerdo 026 de 1977 y, finalmente, por Resolución 679 de 2005 se amplió su extensión y se declaró como Parque Nacional Natural Marino dada la amplia riqueza y belleza de sus ecosistemas de arrecifes coralinos, bosques tropicales, lagunas y manglares (figura 2).

Por otra parte, mediante la Resolución 0456 del 16 de abril de 2003 se ordenó la "elaboración de un modelo sostenible para los archipiélagos de Nuestra Señora del Rosario y de San Bernardo". Ya en su preámbulo, se refiere que estos territorios "están indebidamente ocupadas por particulares que desarrollan actividades que están produciendo efectos nocivos, causando innumerables daños ecológicos a los valores constitutivos del área del Parque y a sus zonas aledañas". Más adelante se hace un diagnóstico de esas acciones incontroladas: la actividad de introducción de flora y fauna; la generación de ruido y vibraciones; la construcción de edificaciones, obras civiles y dragados en la línea de costa; la tala, quema y relleno; la actividad pesquera ilegal; la masificación de actividades de turismo y de recreación; problemas de vertidos sólidos y líquidos y proliferación de fosas sépticas.

En el artículo $2^{\circ}$ de la referida Resolución se destaca el objetivo general: "promover, a través de la formulación de un Modelo de Desarrollo Sostenible, la adopción de medidas que permitan la restauración, conservación, manejo y uso sostenible de los ecosistemas presentes en el área, como apoyo a las comunidades locales, con el fin de lograr el aprovechamiento sostenible y alternativo de los recursos ambientales".

Unos años más tarde, en 2014, fue editado el Plan de Acción Integral como estrategia de administración de los baldíos de los archipiélagos de Nuestra Señora del Rosario y de San Bernardo, en el que trabajaron un número notable de investigadores e instituciones, entre las que se hallan la Universidad de Cartagena. Su principal organismo promotor de ese momento, el INCODER, Instituto Colombiano de Desarrollo Rural (Hoy

con sus prácticas tradicionales de producción, el derecho a la propiedad colectiva sobre las áreas que habrá de demarcar la misma ley. Constitución de Colombia de 1991. https://pdba.georgetown.edu/Constitutions/Colombia/colombia91.pdf

5. Tierras Baldías. Son los terrenos situados dentro de los límites del territorio nacional que pertenecen al Estado y que carecen de otro dueño (Art. 2 de la Ley 70/1993). 
es la Agencia Nacional de Tierras-ANT) y que fungía como administrador de los bienes baldíos de Colombia, publicó otro interesante documento: Observatorio para el desarrollo sostenible de los archipiélagos de Nuestra Señora del Rosario y de San Bernardo (2015).
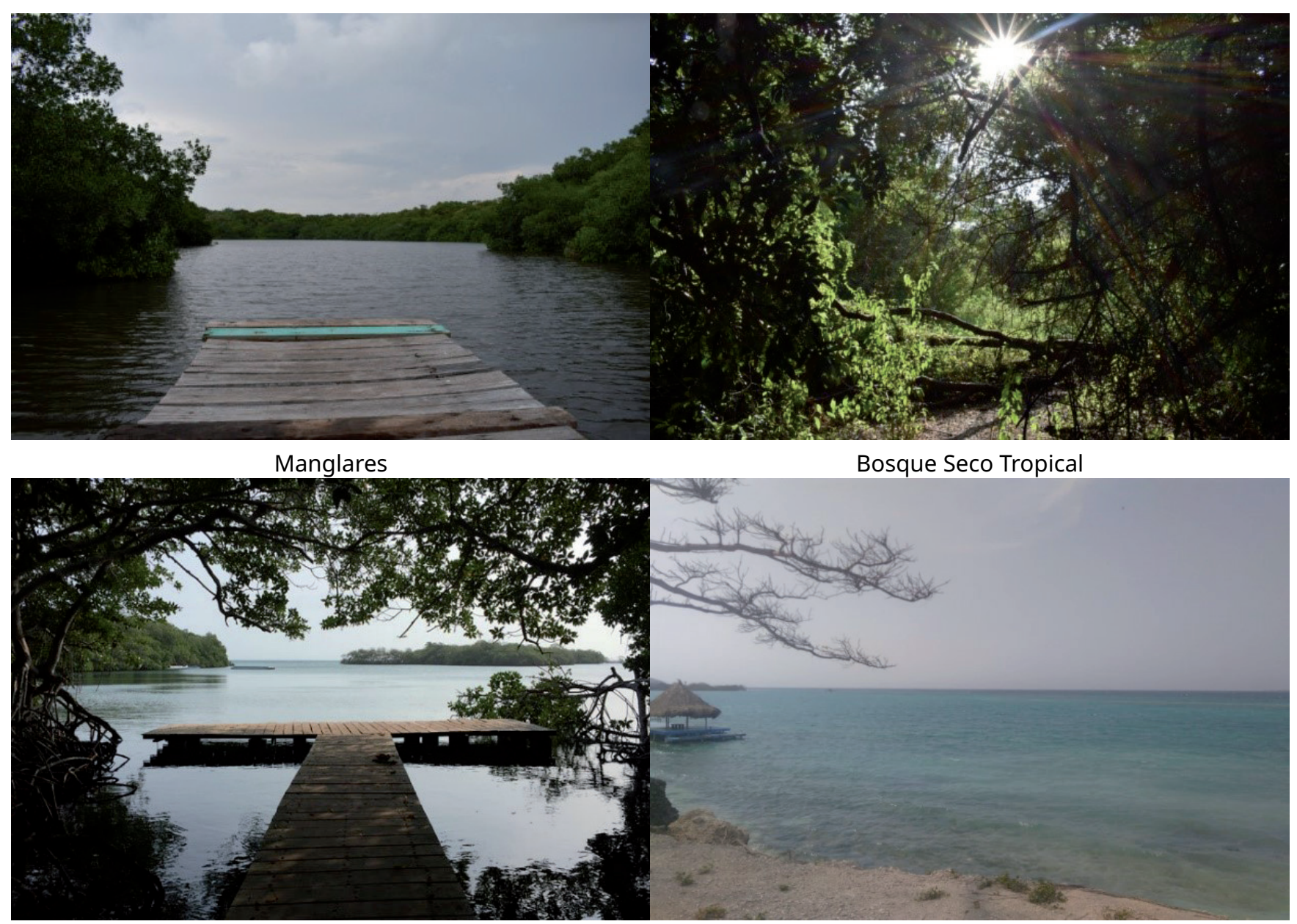

Lagunas costeras (Laguna encantada)

Playas y arrecifes coralinos

Figura 2. Paisajes y ecosistemas de Isla Grande. Fuente: Plan de Marketing de Isla Grande (2018).

\section{METODOLOGÍA Y FUENTES DE INFORMACIÓN}

Se trata de investigaciones mayormente de tipo descriptivo con enfoque cualitativo y cuantitativo, donde se ha trabajado por etapas para lograr el objetivo de este estudio.

La aplicación del etnomarketing como herramienta clave para lograr el desarrollo del destino turístico de una forma sostenible, implicó una serie de fases propuestas por Silva, Ortiz y Giraldo (2016) de la Escuela de Negocios de la Universidad del Norte en Colombia (figura 3), las cuales incluyeron pasos diseñados, teniendo en cuenta los conceptos de Dagoberto Páramo y Elías Ramírez (2017), mediante los cuales se obtuvieron los resultados de este proyecto.

En la etapa de estudio se aplicaron diversas técnicas de recolección de datos, las cuales se describen a continuación:

- Para el análisis de la demanda, se tomó un muestreo no probabilístico por conveniencia a 43 turistas que se encontraban alojados en hoteles que participaron en el estudio, a los cuales se les aplicó una encuesta. Debido a que no existen estadísticas claras oficiales del número de visitantes de la isla se 
optó por este tipo de muestreo, además de necesitar la aprobación de los visitantes para realizarlas, donde no todos deseaban suministrar información.

- Para el análisis de la oferta, se realizó inicialmente un censo In Situ de los alojamientos en los últimos dos meses del año 2017, resultando un total de 29 hoteles, de los cuales accedieron participar en el estudio 18 de ellos, a los cuales se les aplicó un cuestionario. Se realizaron entrevistas a profundidad a dos empresarios nativos de la zona insular para complementar la información sobre las características de esta oferta, así como observación directa no participante, lo que arrojó información cualitativa.

- Para el conocimiento de los aspectos culturales de la población se realizaron entrevistas en profundidad a nativos, observación etnográfica a través de visitas para convivencia con pobladores y por medio del "Encuentro Etnocultural: Difusión, conocimiento y práctica de saberes ancestrales", organizado por el colectivo investigador del proyecto los días 8 y 9 de diciembre de 2017.

Para la etapa de diseño de objetivos y estrategias, se realizaron mesas de trabajo interdisciplinarias y de propuestas iniciales, las cuales fueron revisadas posteriormente por el Consejo Comunitario de Isla Grande. En la elaboración de las estrategias, participó activamente la comunidad, la cual identificó sus potenciales socioculturales. Se validó el trabajo realizado y posteriormente se ejecutó un nuevo trabajo de campo para ajustar con los nativos las estrategias y diseñar las tácticas, correspondientes a la etapa 3.

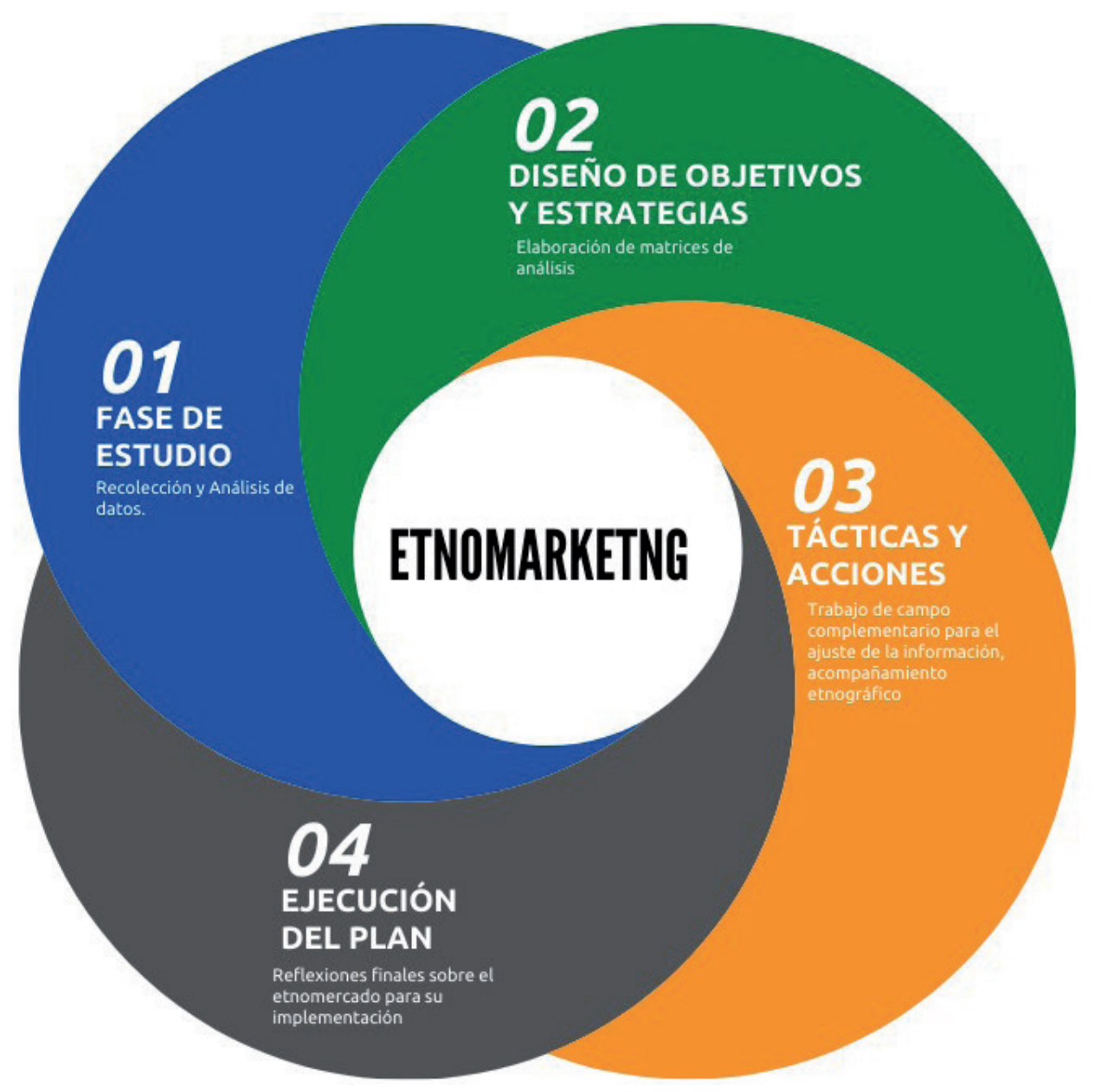

Figura 3. Fases de la aplicación del etnomarketing. Fuente: Elaboración propia, tomando como referencia la adaptación de Silva, Ortiz y Giraldo (2016), para las fases, y Dagoberto Páramo y Elías Ramírez (2017), para los pasos. 
Para la ejecución del plan se contó con la participación activa de la comunidad nativa y del Consejo Comunitario para el proceso de ejecución, donde se aplicaron algunas estrategias centradas en el etnomarketing.

A estas fuentes de información obtenidas de trabajos de campo, recorridos visuales y talleres (figura 4), habría que añadir las de tipo documental. En primer lugar, se ha tenido en cuenta el marco legislativo y planificador tanto de temáticas medioambientales como sociales, mencionadas anteriormente (INCODER, 2014 y 2015) ${ }^{6}$. Otros documentos de referencia han sido los trabajos de Prieto (2007 y 2010) y la Fundación Surtigas (2007). Entre los organismos generadores de información estadística y cartográfica destacan el Servicio de Información Turística de Cartagena (SITCAR) ${ }^{7}$, el Departamento Administrativo Nacional de Estadística (DANE) ${ }^{8}$ de Colombia, el Ministerio de Comercio, Industria y Turismo (MINCIT) ${ }^{9}$, el Instituto de Investigaciones Marinas y Costeras (INVEMAR) ${ }^{10}$ y el Sistema Nacional de Parques Nacionales (SINAP) ${ }^{11}$, que edita trabajos de notable envergadura (Zarza, 2011).

A su vez, hay que considerar los diferentes estudios en los que han participado desde la Universidad de Cartagena, tales como el "Plan de Marketing de Isla Grande" (2018) y la propia tesis doctoral de Villarreal (2017).
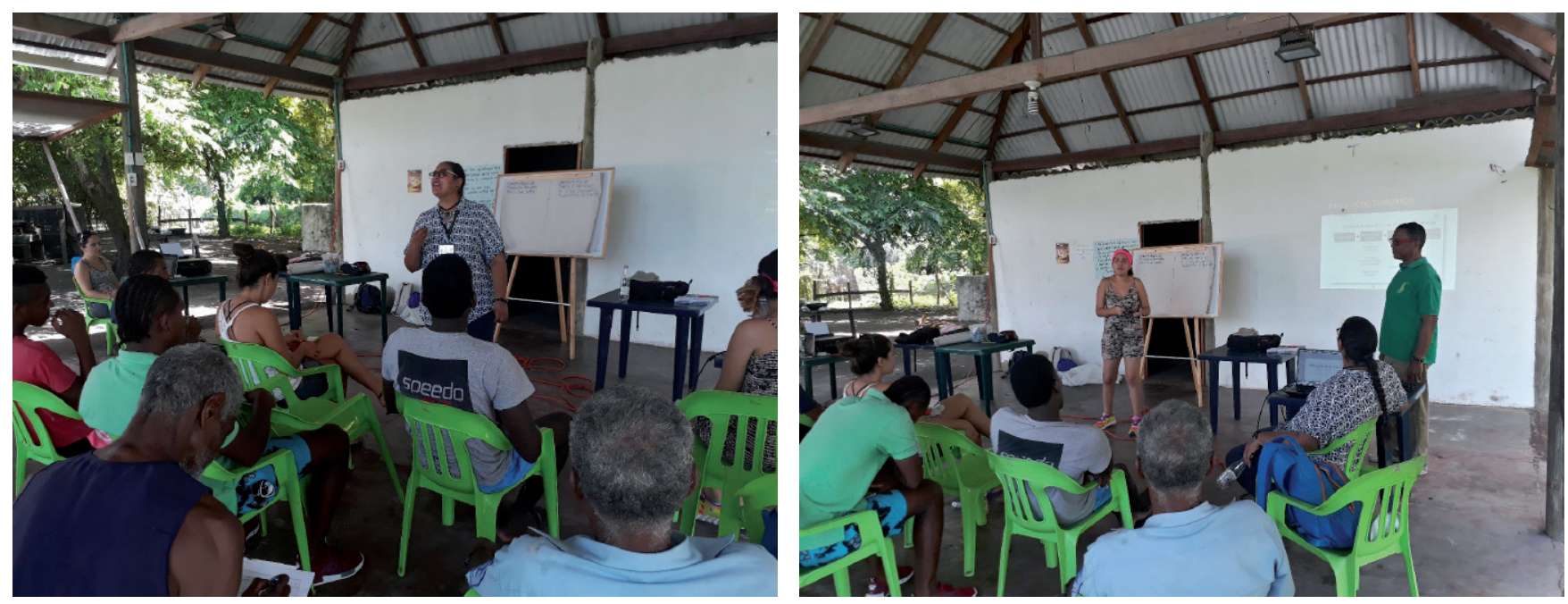

Figura 4. Talleres de socialización y ajuste de estrategias realizados con la comunidad de Isla Grande. Fuente: Autores.

\section{RESULTADOS}

Siguiendo la metodología anterior, se procedió en la etapa de estudio a un análisis y diagnóstico del medio natural y cultural de Isla Grande. Para ello, fue fundamental diversos capítulos:

- Un análisis del macroentorno turístico, en el que se evidencia el progresivo aumento del turismo en Colombia tanto nacional como internacional para pasar a un análisis a escalas de Cartagena de Indias y de Isla Grande. Significativo es que el número de visitantes al PNN Islas del Rosario no ha dejado de crecer, pasando de 305.627 en 2006 a 1.037 .006 en 2017 (Según MINCIT y SINAP), con un aumento espectacular en los dos últimos años (448.479 visitantes en 2015). En poco tiempo se ha convertido en el principal parque nacional colombiano por sus visitas. No obstante, es menor el número de turistas que pernoctan en sus equipamientos de alojamientos (figura 5).

6. Web: https://www.ecured.cu/Instituto_Colombiano_de_Desarrollo_Rural

7. Web: https://turismo.cartagena.es/oficinas_turismo.asp

8. Web: https://www.dane.gov.co/

9. Web: https://www.mincit.gov.co/

10. Web: http://www.invemar.org.co/

11. Web: https://www.parquesnacionales.gov.co/portal/es/sistema-nacional-de-areas-protegidas-sinap/ 
- Un análisis del microentorno de Isla Grande con el objetivo de conocer todos los actores vinculados directa o indirectamente a la actividad turística. Se detallaron los componentes y recursos que describen a Isla Grande como un destino turístico: la accesibilidad y el transporte desde Cartagena de Indias, las infraestructuras en general (energía, agua, residuos sólidos, telecomunicaciones), equipamientos públicos (seguridad-guardia cimarrona-, salud, salas de reuniones, centro cultural "Casa de la cultura" y ofertas culturales, etc.), las posibilidades de transporte, los recursos naturales atractivos (senderos paisajísticos terrestres y acuáticos, las distintas lagunas interiores y costeras, zonas de avistamiento de aves, viviendas con patrimonio ancestral y ecológico), la zonificación de usos del suelo, los recorridos de senderos, y el asociacionismo existente (ecoguías, artesanos, grupo de sabedores ancestrales, alianza de ecohoteles, de danzas y musicales).

Asimismo, se analizó la oferta turística, su infraestructura y promotores de turismo. La oferta hotelera de Isla Grande se ha subdividido entre: hoteles (más convencionales), ecohoteles (con menos comodidades, más natural) y camping.

La naturaleza es el principal atractivo turístico de la isla. Ello origina diferentes actividades de ocio activo: senderismo, recorrido por el poblado de Orika e interacción con la comunidad y actividades deportivas asociadas al mar. Para ello se han propuesto, señalizado y cartografiado diversas rutas y, a su vez, la comunidad local ha activado un conjunto de actividades culturales para los diversos grupos de visitantes y turistas.

También, se ha estudiado la demanda turística que llega a Isla Grande a través de un trabajo de encuestas (marzo de 2017) directamente a los propietarios, administradores de negocios comerciales y turistas. Ello ha permitido obtener un perfil del turista que, de forma muy resumida, es: el $62 \%$ es extranjero y dentro de los mismos, el 34,6\% es de Europa, seguido de Norteamérica con el 30,7\%. Por edad, es mayoritariamente joven; de esta manera el $66,6 \%$ no alcanzan a los 35 años. El 45,8\% llegan en grupos de amigos y familiares y el 29,2\% en pareja. En cuanto a la motivación del viaje, se planteó la posibilidad de responder a diversas opciones quedando los porcentajes de la siguiente manera: conocer lugares nuevos (58,3\%), vivir historias y aventuras nuevas $(50 \%)$, descansar y relajarse $(45,8 \%)$ y para conocer paraísos naturales $(37,5 \%)$. Está claro que la naturaleza es el principal motivo de elección de este destino. A su vez, también las encuestas aclaran las actividades de ocio activo que desean hacer y el nivel de satisfacción conseguido con el destino y con esas actividades, y cuyo resultado es muy elevado.

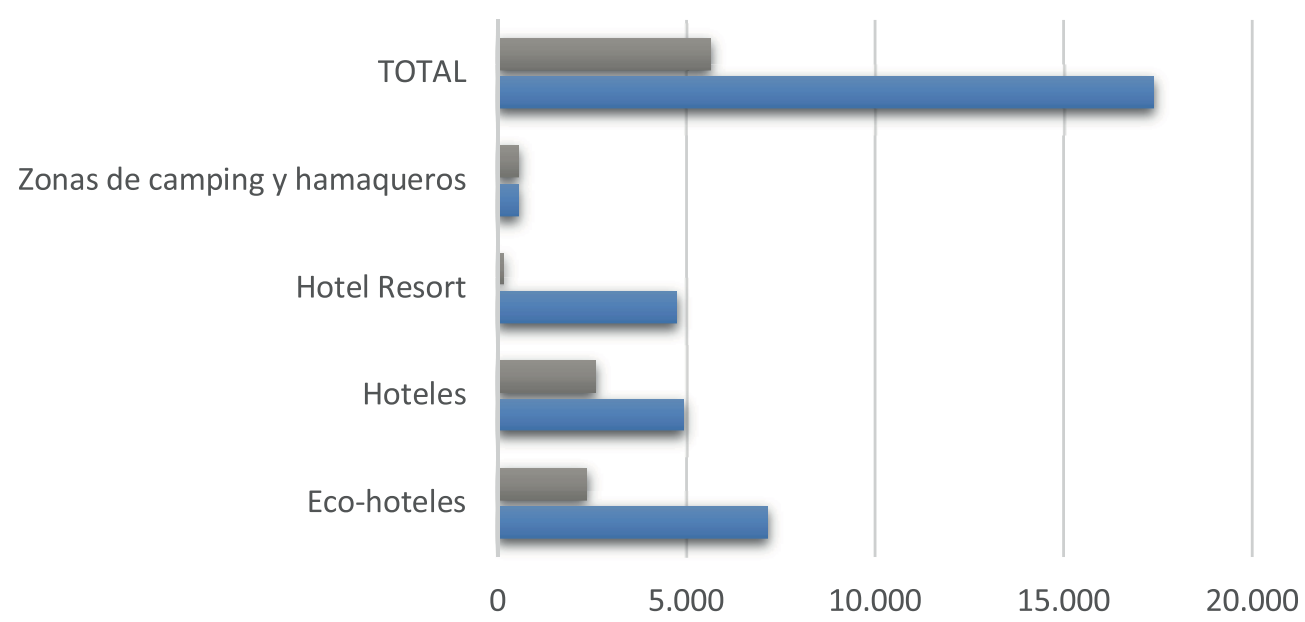

- PROMEDIO MENSUAL DE TURISTAS EN TEMPORADA BAJA

PROMEDIO MENSUAL DE TURISTAS EN TEMPORADA ALTA

Figura 5. Ocupación hotelera en temporadas baja y alta. Fuente: Elaboración propia a partir de datos de MINCIT. Nota Aclaratoria: Temporada alta: Noviembre a febrero, Semana Santa, Vacaciones de Junio-Julio. Temporada baja: Resto de los meses. 
De los diferentes aspectos analizados de la demanda, oferta y destino se puede obtener el siguiente perfil de los turistas que visitan Isla Grande (tabla 1).

Tabla 1. Perfil del turista que visita Isla Grande.

\begin{tabular}{|c|c|c|c|}
\hline Procedencia & Europa & Norteamérica & Suramérica \\
\hline Edad & Entre 18 y 24 años & Entre 45 y 64 años & Entre 25 y 34 años \\
\hline \multirow{4}{*}{ Motivación de Viaje } & Desconectarse de la rutina & Conocer lugares nuevos & Conocer lugares nuevos \\
\hline & Festejo de fecha especial & Desconectarse de la rutina & Aprender cosas nuevas \\
\hline & \multirow{2}{*}{ Conocer paraísos naturales } & \multirow{2}{*}{$\begin{array}{l}\text { Pasar tiempo en familia/ami- } \\
\text { gos y/o pareja }\end{array}$} & $\begin{array}{l}\text { Vivir historias y aventuras } \\
\text { nuevas }\end{array}$ \\
\hline & & & Descansar y relajarse \\
\hline \multirow{3}{*}{ Actividades } & $\begin{array}{l}\text { Paseo paisajístico en ruta en } \\
\text { Kayak por lagunas internas }\end{array}$ & Careteo y/o buceo & Senderismo \\
\hline & Encuentros con familias nativas & \multirow{2}{*}{$\begin{array}{l}\text { Paseo paisajístico en ruta en } \\
\text { Kayak por lagunas internas }\end{array}$} & $\begin{array}{l}\text { Paseo paisajístico en ruta en } \\
\text { Kayak por lagunas internas }\end{array}$ \\
\hline & Saberes ancestrales & & Zona de playas \\
\hline Satisfacción de viaje & $8 / 10$ & $8-9 / 10$ & $9 / 10$ \\
\hline
\end{tabular}

Fuente: Elaboración propia a partir de encuestas realizadas.

Lo expuesto en este capítulo se puede condensar en un análisis DAFO, como base para el diagnóstico (tabla 2), teniendo en cuenta que fortalezas y debilidades se refieren a los aspectos sobre los cuales los diferentes actores del destino turístico pueden realizar cambios de forma directa o adquiridos de forma natural en este caso por ser parte del entorno interno, mientras que oportunidades y amenazas son el entorno externo y por tanto no se pueden modificar de forma directa (Chapman, 2004).

Tabla 2. Análisis DAFO de Isla Grande como destino turístico.

\begin{tabular}{|c|c|}
\hline FORTALEZAS & DEBILIDADES \\
\hline $\begin{array}{l}\text { Cercanía a Cartagena de Indias, uno de los principales destinos turísticos de } \\
\text { Colombia. } \\
\text { Riqueza natural de este destino que ayuda a fomentar el ecoturismo. } \\
\text { Oferta de actividades ecoturísticas como senderismo, avistamiento de aves, } \\
\text { paisajismo, etc. con vistas a diferentes demandas. } \\
\text { Aspectos culturales ancestrales con factores diferenciadores (música, dan- } \\
\text { zas, gastronomía y costumbres). } \\
\text { Formación de grupos asociativos para la gestión del turismo. } \\
\text { Organización y formalización de un órgano administrativo del gobierno } \\
\text { local (Consejo comunitario). } \\
\text { Existencia de personas que conservan y transmiten la historia y la cultura de } \\
\text { la isla. } \\
\text { Práctica de medicina natural ancestral para el manejo de diversas enferme- } \\
\text { dades. } \\
\text { Oferta de servicios ecoturísticos diversos para diferentes segmentos de } \\
\text { mercado. } \\
\text { Recursos ambientales favorecedores de deportes ecoturísticos tales como } \\
\text { careteo, kayaks, buceo, etc. } \\
\text { Existencia de playas muy propicias para el turismo de sol y playa. } \\
\text { Oferta de servicios turísticos complementarios como restaurantes, artesa- } \\
\text { nías, etc. } \\
\text { Paz, tranquilidad y seguridad del destino turístico. }\end{array}$ & $\begin{array}{l}\text { Accesibilidad solo por vía marítima. } \\
\text { Poca promoción del destino turístico de Isla Grande. } \\
\text { Condiciones inadecuadas del centro de salud y falta de } \\
\text { dotación sanitaria adecuada. } \\
\text { Carencia de servicios públicos básicos como agua, ener- } \\
\text { gía eléctrica y alcantarillado. } \\
\text { Debilidad en la recogida de residuos orgánicos e inorgá- } \\
\text { nicos. } \\
\text { Falta de proporcionalidad entre el desarrollo de la } \\
\text { actividad turística y la elevación de calidad de vida de los } \\
\text { nativos. Mayor lo primero que lo segundo. } \\
\text { Poca formación profesional de la población autóctona de } \\
\text { Isla Grande. }\end{array}$ \\
\hline
\end{tabular}


Aumento de la demanda hacia los productos de turismo ecológico. Ecoturismo.

Mantenimiento del producto del turismo de sol y playa.

Crecimiento reciente de la demanda de turistas en el litoral caribeño de Colombia.

Excelentes comentarios de los usuarios en páginas de referencias turísticas a escala mundial.

Interés creciente por el etnomarketing.

Aprovechamiento de recursos tecnológicos para el fomento de los destinos turísticos.

Existencia de organismos de control como DIMAR (Autoridad marítima de Colombia) para la regulación de las actividades marítimas.

Existencia de medios de transportes ilegales que no cumplen con los permisos y condiciones de seguridad.

Limitados recursos de la administración municipal del Distrito de Cartagena de Indias para impulsar nuevos proyectos y actividades promocionales de Isla Grande.

Afectaciones climáticas al destino turístico de Isla Grande.

Peligro de degradación de los atractivos y espacios ecoturísticos por abusos en la capacidad de carga del territorio

Oferta muy similar en destinos cercanos, con pocos factores diferenciadores.

Problemas de ámbito mundial que trunquen los actuales movimientos turísticos.

Fuente: Autores (2018).

A partir de este diagnóstico, y siguiendo la metodología señalada, entramos en las etapas de diseño de objetivos y estrategias. Para ello, se barajaron diferentes matrices entre las que destacan la de ANSOFF, la cual sirve para determinar las estrategias de consolidación de mercados y así reforzar el posicionamiento turístico de Isla Grande mediante el crecimiento del mercado actual y potencial, tomando como estrategia central el etnomarketing.

En cuanto a nuestro ámbito territorial, la matriz de Ansoff ${ }^{12}$ se estructura a partir de cuatro componentes que permiten el fácil desarrollo de estrategias con diferentes enfoques:

\section{Penetración:}

Cruce: "Mercado existente y Producto existente".

Finalidad: Modificar y promover exhaustivamente el producto existente en el mercado actual.

Desarrollo del producto:

Cruce: "Mercado existente y Producto nuevo".

Finalidad: Introducir un producto nuevo en el mercado actual existente.

Desarrollo del mercado:

Cruce: "Mercado nuevo y Producto existente".

Finalidad: Reposicionar y dirigir el producto actual a nuevos mercados.

Diversificación:

Cruce: "Mercado nuevo y Producto nuevo".

Finalidad: Lanzar un producto nuevo a un mercado nuevo.

Esta matriz de Ansoff se ha enfocado a los productos y/o servicios de mayor interés para los visitantes y en la oferta de servicios por parte de la población nativa de Isla Grande (tabla 3).

12. La matriz Ansoff es una técnica de análisis empresarial que proporciona un instrumento de trabajo para detectar e identificar las oportunidades de crecimiento ya que se trata de una herramienta que asocia las estrategias de marketing con la dirección estratégica de la organización. Es una herramienta con enfoque estratégico que permite facilitar la evaluación de las diversas opciones que se acoplen o se adapten al desarrollo del producto turístico con la finalidad de que retorne el mejor potencial. 
Tabla 3. Matriz de ANSOFF en Isla Grande.

\begin{tabular}{|c|c|c|c|c|}
\hline & & & & \\
\hline & & & \multicolumn{2}{|c|}{ MERCADO (SEGMENTO) } \\
\hline & & & Existente & Nuevo \\
\hline \multirow{13}{*}{ 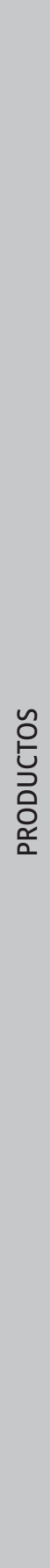 } & \multirow{5}{*}{ 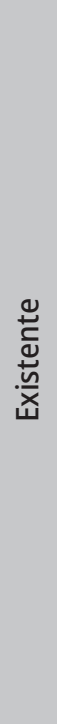 } & $\begin{array}{l}\text { Deportes náuticos (senderismo } \\
\text { acuático, kayak, buceo, careteo y } \\
\text { paddleboard) }\end{array}$ & $\begin{array}{l}\text { Parejas, grupos de amigos, fami- } \\
\text { lias con niños o sin niños. Indife- } \\
\text { rente sexo y edad. }\end{array}$ & - \\
\hline & & Artesanías típicas & $\begin{array}{l}\text { Parejas, grupos de amigos, fami- } \\
\text { lias con niños o sin niños. Indife- } \\
\text { rente sexo y edad. }\end{array}$ & - \\
\hline & & Sabedores ancestrales & - & $\begin{array}{l}\text { Parejas, grupos de amigos, fami- } \\
\text { lias con niños o sin niños. Indife- } \\
\text { rente sexo y edad. }\end{array}$ \\
\hline & & $\begin{array}{l}\text { Ecoturismo (Eco- guías, senderis- } \\
\text { mo terrestre, paisajismo) }\end{array}$ & $\begin{array}{l}\text { Parejas, grupos de amigos, fami- } \\
\text { lias con niños o sin niños. Indife- } \\
\text { rente sexo y edad. }\end{array}$ & - \\
\hline & & Alojamiento Eco - turístico & $\begin{array}{l}\text { Parejas, grupos de amigos, fami- } \\
\text { lias con niños o sin niños. Indife- } \\
\text { rente sexo y edad. }\end{array}$ & - \\
\hline & \multirow{8}{*}{$\stackrel{\circ}{\stackrel{0}{2}}$} & Vivero & $\begin{array}{l}\text { Parejas, grupos de amigos, fami- } \\
\text { lias con niños o sin niños. Mercado } \\
\text { local (comunidad). Indiferente } \\
\text { sexo y edad. }\end{array}$ & $\begin{array}{l}\text { Comunidad académica, colegios } \\
\text { de Cartagena, investigadores. }\end{array}$ \\
\hline & & Cuentería & - & Familias con niños. \\
\hline & & Casa de nativos (Turismo vivencial) & - & Parejas o grupos de amigos. \\
\hline & & Masajes y spa & - & Mujeres (Indiferente edad). \\
\hline & & $\begin{array}{l}\text { Aprendizaje de instrumentos } \\
\text { musicales. }\end{array}$ & $\begin{array}{l}\text { Parejas, grupos de amigos, fami- } \\
\text { lias con niños o sin niños. Indife- } \\
\text { rente sexo y edad. }\end{array}$ & - \\
\hline & & Clases de Bailes típicos & $\begin{array}{l}\text { Parejas, grupos de amigos, fami- } \\
\text { lias con niños o sin niños. Indife- } \\
\text { rente sexo y edad. }\end{array}$ & - \\
\hline & & Deportes (Yoga) & $\begin{array}{l}\text { Parejas, grupos de amigos, fami- } \\
\text { lias con niños o sin niños. Indife- } \\
\text { rente sexo y edad. }\end{array}$ & - \\
\hline & & Sendero interpretativo ambiental & $\begin{array}{l}\text { Avistamiento de aves y otro tipo } \\
\text { de fauna. } \\
\text { Recorrido por lagunas interio- } \\
\text { res, manglares y el bosque seco } \\
\text { tropical. }\end{array}$ & $\begin{array}{l}\text { Comunidad académica, colegios } \\
\text { de Cartagena, investigadores. }\end{array}$ \\
\hline
\end{tabular}

Fuente: Autores (2018).

A partir del cruce realizado en la matriz ANSOFF se muestra que:

- Los productos nuevos son derivaciones de los ya existentes, ampliando la diversificación de la oferta preexistente de Isla Grande, ya que promueven la cultura ancestral que caracteriza a la comunidad de Isla Grande. Cabe resaltar que la identificación de los mismos e inclusión en el portafolio de servicios ofertados por el destino fue posible gracias al aporte de la comunidad y su participación en las mesas de trabajo. 
- Los mercados objetivos son existentes o actuales. Por tal razón se debe desarrollar esos productos y/o servicios acordes a las nuevas expectativas de los turistas que viajan a Isla Grande para generar fidelización.

- Se desarrollan nuevos mercados dentro de la caracterización ya existente, debido al nacimiento de nuevas actividades enfocadas a una demanda turística diversificada y el fomento de visitantes residentes en Cartagena, lo que mantendrá una demanda permanente, todas enfocadas en el etnomarketing.

Además de las estrategias de crecimiento para mercados turísticos actuales y potenciales, se diseñaron otras centradas en el cruce de variables de la matriz DOFA, dentro de las cuales destacan los siguientes objetivos estratégicos:

- Reforzar el posicionamiento de Isla Grande como uno de los destinos turísticos de mayor preferencia en la región del caribe colombiano en los próximos cinco años.

- Fortalecer prácticas ecoturísticas que permitan el aprovechamiento de los recursos de la isla para su sostenibilidad, mediante actividades como la mejora de la señalética, la capacitación para la preservación de recursos naturales de nativos y visitantes y la implementación de puntos de información turística.

- Establecer alianzas estratégicas entre nativos y los empresarios para robustecer los productos/servicios turísticos.

- Fidelizar a los clientes mediante la generación de "valor", dándole más allá de lo esperado, con experiencias que generen un recuerdo y una difusión directa de este enclave turístico.

Pero este trabajo de investigación y planificación estratégica ha de llevar también una etapa de formulación de tácticas y acciones. Para ello, se dispuso de un cuadro operativo ${ }^{13}$ para cada una de las variables en las que se resumen las estrategias, las tácticas, los indicadores esperados y los responsables más directos. Estas recomendaciones y buen fin de las acciones dependerán del compromiso de los empresarios, de la población nativa en general y, en especial, de su Consejo Comunitario.

Para el seguimiento se deberá evaluar periódicamente el grado de avance del plan de marketing y ver si se presentan desviaciones que, en caso de producirse, se propondrían análisis de causas y medidas correctivas.

Para el control se establecen diversos indicadores con vistas al seguimiento interno por parte del Consejo Comunitario y el Comité turístico: indicadores generales y específicos para valorar el desarrollo turístico; la comunicación interna en la isla para generar retroalimentación y aportaciones para las medidas correctivas en caso de presentarse; realización de memorias de evaluación; y análisis y valoración final pasados no menos de 3 años. Esta última fase no se ha podido comprobar como consecuencia de la irrupción de la crisis del COVID-19 desde la primavera del 2020.

\section{DISCUSIÓN}

Esta aportación ha servido para comprobar las hipótesis iniciales. Isla Grande posee unos recursos naturales y culturales muy singulares que se convierten en factores de atracción para una demanda turística que busca el contacto con la naturaleza, el ocio activo y la interacción con los valores culturales de la población autóctona. Hace parte de la oferta turística de "sol y playa", el cual se centra en el aprovechamiento de la ubicación geográfica en zonas costeras (Santos-Lacueva et al., 2020), pero genera factores diferenciadores frente a otros destinos al combinar también bosques y lagunas, lo que permite realizar otras actividades, como el senderismo, por ejemplo, que amplía las posibilidades de fortalecer el portafolio para diversos segmentos de mercado.

Pero, no basta con ofrecer lo que la naturaleza aporta para que un destino turístico sea exitoso. Es aquí donde los saberes ancestrales, que hacen parte de la cultura y tradición del sitio, termina creando experiencias

13. Por extensión se omite este cuadro en esta aportación. 
únicas que, aprovechada con las bondades geográficas, genera valor agregado. Isla Grande tiene gran riqueza cultural que quedó evidenciada durante la investigación. Los saberes ancestrales son valorados por la comunidad y los adultos mayores trasladan a los más jóvenes sus conocimientos. Algunas de estas actividades no eran identificadas por la población autóctona como productos potenciales que pueden generar factores diferenciadores, por lo que el etnomarketing como herramienta les permitió valorar su patrimonio inmaterial para trasmitirlos a los visitantes. Solo fue posible la construcción de un portafolio único y diversificado por segmentos gracias a la interacción que se logró con la comunidad para conocer realmente sus costumbres y tradiciones a través de eventos y mesas de trabajo comunitario, donde primó el respeto. Se pudo identificar segmentos de mercados reales y potenciales para brindar portafolios adaptados a los tipos de visitantes, lo que puede generar experiencias únicas y enriquecedoras que fidelicen a los turistas no solo a volver sino a recomendar las excelencias de este destino. Esta es la principal aportación de esta investigación y lo que enfoca hacia donde se debe trabajar para mejorar el desarrollo turístico e integral de este destino.

En consecuencia, se identificaron las potencialidades ecoturísticas de este territorio a través de un ejercicio comunitario de análisis DAFO, que permitió expandir la oferta, despertando el interés de los más jóvenes por seguir conservando la tradición y proyectar el crecimiento del mercado utilizando la Matriz de Ansoff.

Asimismo, siguiendo a Martínez (2020) es necesaria una planificación estratégica que analice bien esos recursos y potencialidades ecoturísticas que han de ser abordadas en toda su dimensión si se quiere desarrollar y posicionar nuevos productos ecoturísticos y fortalecer los existentes. Solo de esta manera, Isla Grande no caería en un modelo turístico depredador como refieren Quintana (2020) y Martínez (2020) y, a su vez, sería una importante apuesta para la mejora de las economías locales, como expresa De Madariaga (2019).

Estamos de acuerdo con Páramo (2015), Salas (2018) y Ortiz (2016) en que el ecoturismo, el etnodesarrollo y el etnomarketing se convierten de forma integrada en importantes bazas para los intereses, en este caso, de Isla Grande. Los dos primeros, a la par, como modelo de desarrollo turístico al que se aspira ofreciendo actividades relacionadas con los recursos naturales y culturales. El tercero, como un instrumento de planificación en el que se hace hincapié en los valores culturales y en el propio compromiso de la población con el medio ambiente y el turismo. Otros diversos autores analizados en esta investigación destacan igualmente la importancia del ecoturismo.

Igualmente, se coincide con otros autores e instituciones que han estudiado Isla Grande (Zarza, 2011; INVEMAR, 2005; UAESPNN, 2006; MADS, 2012; INCODER, 2015; MINCIT, 2019), al considerar que este territorio insular posee factores potentes y diferenciadores a través de una oferta de experiencias únicas y que pueden posicionar este destino ecoturístico dentro del mar Caribe y con vistas a demandas turísticas lejanas a escala internacional. De esta manera, lejos podría quedar la pobreza secular de esta isla como refería Prieto (2010).

Se ha interactuado con la comunidad local, tanto con sus habitantes y empresarios, como directamente con el Consejo Comunitario, quien juega un papel fundamental en el desarrollo de estrategias. Pero estas no serán exitosas si no se fomenta una cultura de la gestión estratégica y la planificación. Si bien el destino ha crecido por su riqueza natural, se debe aumentar el tiempo promedio del visitante atrayendo su interés hacia aspectos del cotidiano vivir que lo mantengan ocupado y los interese a aceptar sus tradiciones. Esto solo es posible con un pensamiento estratégico a partir del cual se derivan acciones de corto plazo que contribuyan a generar experiencias positivas, únicas e irrepetibles.

Si se improvisa, no se analiza el mercado y se ofrece a todos lo mismo, no se crea valor agregado e impedirá que se regrese más de una vez al destino. De ahí el compromiso científico y social de entidades como la Universidad de Cartagena, para empoderar a la comunidad en la preservación de lo ecológico, lo cultural y el saber ancestral, ayudando a la población autóctona en mejorar su nivel de vida. No ha sido el propósito de los investigadores imponer ideas y acciones desde el plano académico sino de interactuar, con un contacto mutuo y un conocimiento recíproco. Por tanto, hay mucho en los resultados de estas investigaciones del propio saber y de las iniciativas de sus líderes sociales y otros distintos participantes.

Las singularidades y la evolución de este territorio pueden generar nuevas investigaciones y desde distintas perspectivas y especialidades. También creemos que nuestras aportaciones pueden persistir en el tiempo en favor de este territorio. 


\section{CONCLUSIONES}

Isla Grande, dentro del Archipiélago de Islas del Rosario y a escasa distancia por mar de Cartagena de Indias (45 km y una hora de navegación), presenta una sobresaliente riqueza natural de playas, lagunas, bosque seco tropical y arrecifes marinos. A ello se une su patrimonio cultural, con un componente poblacional de origen africano. A su vez, es singular la existencia de una propiedad colectiva reconocida legalmente después de años de duras reivindicaciones y litigios.

Sin duda, hay enclaves en el Caribe colombiano y de otros países cercanos igualmente interesantes, pero difícilmente podemos encontrar las singularidades culturales y los atractivos de este enclave insular, cuya economía es ya muy dependiente del turismo dado que las actividades ancestrales de la pesca no son suficientes para escapar de la pobreza y mantener una calidad de vida digna. Por otra parte, en Isla Grande le dan un protagonismo especial a su patrimonio natural y cultural para su progreso económico, social y cultural, así como para la conservación y fortalecimiento de su identidad local. De esta manera, apuestan por un modelo de desarrollo basado en el ecoturismo y el etnodesarrollo.

Es de destacar que el aumento y las nuevas tendencias de la demanda del turismo internacional y la recuperación del turismo nacional colombiano ofrecen nuevas oportunidades para alcanzar el modelo de turismo sostenible y las estrategias que aquí se proponen, de manera que permitan lograr el desarrollo de Isla Grande y el conjunto del Archipiélago de Isla del Rosario como destino turístico. Lo ideal, sin duda, es que ese crecimiento de los índices turísticos mejore al mismo par que el nivel y las condiciones de vida de sus habitantes.

La actual crisis del Covid ha cercenado unas cifras de turismo que iban en aumento y un Plan de marketing en Isla Grande que estaba en desarrollo. Esta crisis muestra también la debilidad de las economías muy volcadas en el turismo. Hemos sido testigos del cierre de establecimientos y de la ruina de diversas empresas de alojamiento y de ocio activo, como también en la cercana Cartagena de Indias. Muchas esperanzas, ideas y acciones emprendedoras se han visto truncadas por la imposibilidad de llegar turistas, especialmente internacionales. No obstante, queda en Isla Grande un compromiso social y un modelo de desarrollo local que proseguirá una vez que finalice esta crisis de escala mundial. Este modelo de desarrollo se convierte en un desafío para la sostenibilidad de este espacio natural e, igualmente, es importante para el cumplimiento de la Agenda 2030 y sus Objetivos de Desarrollo Sostenible (ODS).

\section{Financiación}

Este artículo se constituye en uno de los resultados en el marco del Proyecto "Diseño e implementación del sendero ecoturístico estratégico para el aprovechamiento sostenible de los ecosistemas de manglar y bosque seco tropical en Isla Grande", financiado en el marco de la convocatoria 750 de 2016, Ideas para el Cambio Bio Capítulo 2 de Colciencias. Universidad de Cartagena-COLCIENCIAS

\section{Agradecimientos}

Agradecemos especialmente a la Comunidad del poblado de Orika (Isla Grande) y al Consejo Comunitario de Isla del Rosario.

\section{Declaración responsable y conflicto de intereses}

Las/os autoras/es declaran que no existe ningún conflicto de interés con relación a la publicación de este artículo. Las tareas se han distribuido de la siguiente manera: Las/os tres autoras/es han participado en la revisión bibliográfica, el diseño de la metodología y la redacción del artículo. La realización del análisis gráfico y cuantitativo ha estado a cargo de Paola Mouthón-Ramos. 


\section{REFERENCIAS}

Bonfil Batalla, G. (1982). Etnodesarrollo: sus premisas jurídicas, políticas y de organización. América Latina: etnodesarrollo y etnocidio. Ediciones Flacso. https://biblio.flacsoandes.edu.ec/libros/digital/40151.pdf

Ceballos-Lascuráin, H. (1996). Tourism, Ecotourism and Protected Areas. Unión Mundial para la Naturaleza. https://doi. org/10.2305/IUCN.CH.1996.7.en

Chapman, A. (2004). Análisis DOFA y análisis PEST. https://degerencia.com/articulo/analisis_dofa_y_analisis_pest/

Corte Constitucional, Sala Sexta de Revisión (2012, 27 de agosto). Sentencia T-680 expediente T-1.842.451. Colombia. https://www.dejusticia.org/wp-content/uploads/2017/04/fi_name_recurso_541.pdf

Cortecero Bossio, A., Villadiego Lorduy, J. R., Sánchez Castillo, J. R., García Corrales, N., Florville Alejandre, T. R., Espinosa Corrales, D. E. \& Payares Ramos, P. (2020). Reflexiones sobre Etnodesarrollo: caso el Palenque de San Basilio, Bolívar, Colombia. Repositorio Universidad Pontificia Bolivariana. https://repository.upb.edu.co/handle/20.500.11912/8485

De Madariaga, C. J. (2019). El turismo patrimonial: la cultura en venta. En J.A. Márquez \& J.L. Llamas (coord.). Hélices y anclas para el desarrollo local (pp. 803-812). Universidad de Huelva.

Decreto 1745 de 1995 mediante el cual se adopta el procedimiento para el reconocimiento del derecho a la propiedad colectiva de las tierras de comunidades negras. Colombia. https://www.minagricultura.gov.co/Normatividad/Decretos/ Decreto\%20No.\%201745\%20de1995.pdf

Giraldo, M. \& Juliao, D. (ed.) (2016). Gerencia de Marketing. ECOE Ediciones, Universidad del Norte. https://www.ecoeediciones.com/wp-content/uploads/2016/12/Gerencia-de-Marketing-1ra-Edici\%C3\%B3n.pdf

INCODER (2014). Plan de acción para la administración sostenible de los baldíos de los archipiélagos de Nuestra Señora del Rosario y de San Bernardo. Incoder-Universidad de Bogotá Jorge Tadeo Lozano. http://observatorio.epacartagena. gov.co/ftp-uploads/pub-irsb-plan-de-accion-integral-como-estrategia-de-administracion-de-los-baldios-de-los-archipielagos-de-nuestra-senora-del-rosario-y-san-bernardo.pdf

INCODER (2015). Observatorio para el desarrollo sostenible de los archipiélagos de Nuestra Señora del Rosario y de San Bernardo. Incoder-Universidad de Bogotá Jorge Tadeo Lozano. http://observatorio.epacartagena.gov.co/ftpuploads/pub-irsb-observatorio-para-el-desarrollo-sostenible-de-los-archipielagos-de-nuestra-senora-del-rosario-y-de-san-bernardo.pdf

INCODER (2014, 8 de mayo). Tierra de las Comunidades Negras. Resolución 3393 de 2014. Instituto Colombiano de Desarrollo Rural. https://diario-oficial.vlex.com.co/vid/inaplican-culo-comunera-orika-stico-511737690

INVEMAR-UAESPNN-NOAA (2005). Establecimiento de un sistema de monitoreo socioeconómico para el Parque Nacional Natural Corales del Rosario y San Bernardo-Sector San Bernardo, Caribe colombiano, Santa Marta. Instituto de Investigaciones Marinas y Costeras. Inédito. https://www.ncei.noaa.gov/data/oceans/coris/library/NOAA/CRCP/project/1395/SocEconMonitoring_SanBernardoColombia.pdf

Kotler, P. \& Keller, K. (2012). Dirección de marketing. Pearson Educación, 14ª edición. http://www.montartuempresa.com/ wp-content/uploads/2016/01/direccion-de-marketing-14edi-kotler1.pdf

Ley 70 de 1993 sobre comunidades negras. Derechos y deberes de las comunidades negras a tener sus propias formas de organización en los territorios. http://www.mininterior.gov.co/la-institucion/normatividad/ley-70-de-1993

Llamas Chávez, J.L. (2020). Participación comunitaria en el proceso de conservación del patrimonio territorial en el Corregimiento de La Boquilla (Cartagena de indias - Colombia). Universidad de Huelva. http://hdl.handle.net/10272/18468

MADS (2012). Modelo de Desarrollo Sostenible para el área Marina Protegida de los Archipiélagos Nuestra Señora del Rosario y de San Bernardo 2013-2014. Ministerio de Ambiente y Desarrollo Sostenible, Bogotá.

Magio, K. O. \& Valdez, M. V. (2019). El ecoturismo en las reservas de la biósfera: Prácticas y actitudes hacia la conservación. PASOS Revista de Turismo y Patrimonio Cultural, 17(1), 97-112. https://doi.org/10.25145/j.pasos.2019.17.007

Martínez Menárguez, B. (2020). Hacia un modelo turístico sostenible y competitivo en Costa Rica. Universidad de Alicante. https://rua.ua.es/dspace/bitstream/10045/107820/1/HACIA_UN_MODELO_TURISTICO_SOSTENIBLE_Y_COMPETITIV_Martinez_Menarguez_Bibiana.pdf

MINCIT (2019). En 2019 el turismo en Colombia rompió récords. Nota de prensa. Ministerio de Comercio, Industria y Turismo. Colombia. https://www.mincit.gov.co/prensa/noticias/turismo/en-2019-el-turismo-en-colombia-rompio-records\#: : :text=Del\%20total\%20de\%20visitantes\%20no,el\%20exterior\%20(cifra\%20preliminar). 
Ministerio de Ambiente, Vivienda y Desarrollo Territorial (2003, 16 de abril). Resolución número 0456 por medio de la cual se ordena la elaboración de un modelo de desarrollo sostenible para los Archipiélagos de Nuestra Señora del Rosario y de San Bernardo. Colombia. https://www.parquesnacionales.gov.co/portal/wp-content/ uploads/2013/12/0456.pdf

Ministerio de Ambiente, Vivienda y Desarrollo Territorial (2005, 31 de mayo): Resolución 679 de 2005 por el que se declara el Área Marina Protegida de los Archipiélagos del Rosario y de San Bernardo. Diario Oficial n 45.927. Colombia. https://www.icbf.gov.co/cargues/avance/docs/resolucion_minambientevdt_0679_2005.htm

Molina Molina, C. (2011). Ecoturismo en Colombia: una respuesta a nuestra invaluable riqueza natural. Turismo y DesarroIlo Local, 2011, issue 10. https://econpapers.repec.org/article/ervturdes/y_3a2011_3ai_3a10_3a32.htm

Ortiz, N. (2016). Etnomarketing: estrategias de negocio desde las raíces culturales. 360: Revista de Ciencias de la Gestión, Departamento Académico de Ciencias de la Gestión de la PUCP, n 1. https://doi.org/10.18800/360gestion.201601.005

Páramo Morales, D. (2015). Etnomarketing, la dimensión cultural del marketing. Gerencia Libre, 1. https://revistas.unilibre.edu.co/index.php/gerencia_libre/article/view/3167/2577

Pereiro, X. (2020). Antropología del turismo: ¿para qué? ¿y para quién? Crítica de la razón turística. Disparidades. Revista de Antropología, 75(1), e001b. https://doi.org/10.3989/dra.2020.001b

Presidencia de la República (1991). Constitución Política de Colombia de 1991. https://pdba.georgetown.edu/Constitutions/Colombia/colombia91.pdf

Prieto Bustos, W.O. (2007). Estudios socioeconómico y plan de desarrollo local para las Islas del Rosario. Convenio Fundación Surtigas-Universidad de Cartagena, Mimeo. https://surtigas.com.co/cargar_imagen.php?id=242\&tipo=6\&thumbnail=FALSE

Prieto Bustos, W.O. (2010). Desarrollo local en Isla Grande. Un modelo probabilístico para la pobreza. Semestre Económico, 13(26), 11-31. Universidad de Medellín (Colombia). file://C:/Users/USUARIO1/Desktop/Art\%C3\%ADculo\%20 de\%20Pasos/Bibliograf\%C3\%ADa/Dialnet-DesarrolloLocalEnIslaGrandeUnModeloProbabilisticoP-3236870.pdf

Quintana Cataño, M.D.M. (2020). Turismo en los pueblos indígenas de Colombia. Universidad de Bogotá. https://expeditiorepositorio.utadeo.edu.co/handle/20.500.12010/18953?locale-attribute=en

Ramírez, E. \& Páramo, D. (2017). Etnomarketing. La dimensión cultural del marketing. Klasse editorial.

Salas Obregón, F. (2018). Reinvención de la cultura en la actividad turística del mundo andino quechua: caso Urubamba-Cusco. Universidad Nacional del Altiplano. http://revistas.unap.edu.pe/epg/index.php/investigaciones/article/view/960

Santos-Lacueva, R., Clavé, S.A. \& Saladié, Ò. (2017). Discontinuidades y limitaciones de los últimos planes turísticos de España en relación a la sostenibilidad ambiental del turismo de sol y playa. Cuadernos de Turismo, 40, 599-626. https://doi.org/10.6018/turismo.40.310121

Silva, H., Ortiz, M. \& Giraldo, M. (2016). Plan de Marketing. Gerencia de Marketing. Vol. 1. ECOE Ediciones, Universidad del Norte.

SITCAR (2020). Más de 2.700.000 viajeros eligieron visitar Cartagena de Indias en 2018. Nota de prensa. Servicio de Información Turística de Cartagena. https://indiasdigitaltravel.com/actualidad/mas-de-2700-000-viajeros-eligieronvisitar-cartagena-de-indias-en-2018-sitcar/

Sosa, M. \& DAbusco, D. S. (2020). MUTANTUR: una experiencia de turismo para la integración social. Universidad Nacional de Avellaneda. http://coninformacion.undav.edu.ar/537.html

UAESPNN (2006). Plan de Manejo del Parque Nacional Natural Corales del Rosario y San Bernardo. Unidad Administrativa Especial del Sistema de Parques Nacionales Naturales de Colombia. Territorial Costa Caribe. Cartagena, Colombia. https://www.parquesnacionales.gov.co/portal/wp-content/uploads/2013/12/Corales.pdf

Vargas del Río, D. (2010). Espacios comunitarios sujetos a conservación y turismo: retos para la gestión costera participativa [Tesis doctoral, Universidad Politécnica de Cataluña].

VV.AA. (2018). Plan de Marketing de Isla Grande. Consejo Comunitario de Islas del Rosario y Universidad de Cartagena, Grupo Colciencias. Inédito.

Zarza, E. (ed) (2011). El entorno ambiental del Parque Nacional Natural Corales del Rosario y San Bernardo (PNNCRSB). 1a edición, Colombia: Parques Nacionales Naturales de Colombia. https://docplayer.es/24609015-El-entorno-ambiental-del-parque-nacional-natural-corales-del-rosario-y-de-san-bernardo.html 